\title{
General Discussion to Papers of Miss Anne Evans, Miss Gill Arnott, Mr Gwilym Jones, Mrs M. A. Thompson and Mrs B. Richards
}

Professor V. PAeslack (Chairman). I think there are a number of questions and I open the discussion for these five papers.

DR CHESHIRE (U.S.A.). I was particularly interested in the excellent paper which Mrs Richards has just read. The placement of the tetrplegic into long-term care facilities is indeed a universal headache. I am trying to amalgamate some impressions from Britain and the United States. In the United States I know no alternative to what we call the nursing home, which is the lowest form of geriatric care and totally soul destroying. At the other end of the scale I personally have seen nothing which appeals to me better than Lacorde which I have seen. It is not perfect but I think it is probably the best I have seen. This is merely a lead-up to a question for Mrs Richards. Mrs Richards, on the basis of your experience, which is so infinitely greater than mine, do I understand you to be saying that you are advocating the establishment of exclusively tetraplegic long-term care facilities? Because I have a great respect for that opinion, yet I have also heard people talking about the tetraplegic ghetto. Where do we balance?

Mrs RichaRds (G.B.). No, I don't believe in ghettoes of any kind, but from my observations, from the people I have spoken to and staff, I feel that our patients are very unhappy to be together with people of other disabilities and I think we have got to try and educate them to think otherwise. They are just other people and I think this is what we don't have time to discuss with them beforehand. One mentions to them, You will see people who don't look like you or who can't think as you do: but this isn't enough, I mean these are just words, one needs to take them to see other people to be with them for a while. I think that many of our patients that go into institutional care have unfortunately made up their minds before they go that they are not going to like other people with other disabilities. There was a time when the Cheshire Home Foundation were thinking in terms of setting up a home for spinal cord injuries entirely; it never quite came off the ground. I think people should mix up; I'm all for mixing.

Chairman. Thank you Mrs Richards.

Dr Young (U.S.A.). Both David Cheshire and I stood up simultaneously and independently to respond to these wonderful papers we've had this afternoon on this very difficult subject and David stole my question actually when he asked Mrs Richards about the home or the place for the tetraplegic. We have concern about creating the ghetto. I would ask you with your experience what would you recommend as the ultimate size, working from your cadre living situation, for a tetraplegic?

MRS RICHARDS. I think I can only point to our own Sir Ludwig Guttmann Young Disabled Unit attached to this hospital which has 30 beds for tetraplegics and spinal cord injuries with ten other disabilities, and that seems to work extremely well. I think if one has to go outside a young disabled unit where there are other disabilities then you need at least six spinal cord injury patients to form a sort of nucleus and have some sort of communication. At the hospital in Putney for incurables-a terrible name-they were able to open up a new unit and they only have a nucleus of six spinal cord injury patients, and this seems to work very well because they form a sort of family of their own and they have common interests and common bonds and they can rub along with other people as long as they've got someone of their own kind and that's fair enough.

DR MENTER (U.S.A.). You addressed yourself to the outcome of those patients who returned to residential living facilities. Did you have any impression as to the reactions of those substantial number of people who were discharged to home-living situations and their acceptance of that living situation in the absence of other handicapped people in their living area.

MRS RICHARDS. You are talking about my I96 that I followed up.

DR MENTER. Correct. 
MRS RICHARDS. Who went home?

DR MENT ER. Who went home. What happened to those people and the fact that they were not necessarily living in an area that was a handicapped co-habitation?

MRS RICHARDS. I did follow them up either by letter or phone call to describe them as it were for the purpose of this paper, and I think that all of them on the whole are fairly well established at home. If they've made friends with other patients when they were here, they continue the friendship. When we went to boarding school, we made friends, we keep up with those we want to keep up with and I don't think the disabled are any different in this respect. They make their own lives, they're just people, they go home, they go back to work or they don't go back to work; they have their families and the disabled they want to keep up with, not because they're disabled, necessarily, just because they are people they happen to like. Or they come back and they use the sports facilities. I think those who go home settle at home, that's fine. I don't think they feel the need to meet other disabled people necessarily unless they just like them.

Professor M. WEISS (Poland). I should like to congratulate the group at Oswestry which showed such interesting follow-up studies. In my own country, in my own region, we follow up around 300 tetraplegics we discharged. In this condition we have actually in Central Europe the only possibility to create a proper exclusive quarters for young tetraplegics is within specialised rehabilitation institutions like I saw in Perth, Australia. In most countries in my region the maintenance of electrical equipment creates much difficulties. We can claim an astounding kind of climate within this group. They can study, and this solution I believe is in many countries the only solution to give a logical line that all medical efforts should be continued.

Chairman. Thank you Professor Weiss. I think we have to proceed, we have another paper. There is a little bit of time. May I now ask Mr Mark Kieff from the New England Spinal Cord Injury Foundation to give us his paper. 